\title{
PENGARUH DISIPLIN KERJA TERHADAP PRODUKTIVITAS KERJA KARYAWAN PT PERKEBUNAN NUSANTARA IV (PERSERO) UNIT USAHA PABATU
}

\author{
Yulia Andini' ${ }^{1}$ Yusniar Lubis ${ }^{2}$, Rahma Sari Siregar* \\ ${ }^{1}$ Agribisnis, Fakultas Pertanian, Universitas Medan Area, Indonesia \\ Diterima: Agustus 2019 Disetujui: Oktober 2019 Dipublish: Oktober 2019
}

*Coresponding Email: lsiregarrahmasari@yahoo.co.id

\begin{abstract}
Abstrak
Penelitian ini dilakukan bertujuan untuk mengetahui pengaruh disiplin kerja terhadap produktivitas kerja karyawan pada PT. Perkebunan Nusantara IV (Persero) Unit Usaha Pabatu. Populasi dalam penelitian ini adalah seluruh karyawan bagian afdeling, teknik/pengolahan, dan umum pada PT. Perkebunan Nusantara IV (Persero) Unit Usaha Pabatu sebanyak 1031 orang. Jumlah responden yang digunakan dalam penelitian ini sebanyak 104 orang. Penelitian diperoleh dari hasil uji t pada variabel mematuhi semua peraturan perusahaan yaitu 2,652> Ttabel $=1,980$ menyatakan bahwa mematuhi semua peraturan perusahaan berpengaruh positif dan signifikan terhadap produktivitas kerja karyawan. Penggunaan waktu secara efektif diperoleh yaitu 3,069< Ttabel = 1,980 menyatakan bahwa penggunaan waktu secara efektif berpengaruh positif dan signifikan terhadap variabel Produktivitas kerja karyawan. Tanggung jawab dalam pekerjaan dan tugas yaitu 5,467>Ttabel = 1,980 menyatakan bahwa tanggung jawab dalam pekerjaan dan tugas berpengaruh positif dan signifikan terhadap produktivitas kerja karyawan. Tingkat absensi yaitu $1,200<$ Ttabel $=1,980$ berpengaruh positif dan tidak signifikan terhadap produktivitas kerja karyawan. Hasil uji simultan diperoleh yaitu 262,880 > 2,31 menyatakan bahwa disiplin kerja secara simultan berpengaruh positif dan signifikan terhadap produktivitas kerja karyawan. Dan nilai R yang diperoleh sebesar 0,884. Angka tersebut menunjukkan bahwa sebesar 88,4\% produktivitas kerja dijelaskan oleh variabel disiplinkerja.
\end{abstract}

Kata Kunci: Disiplin Kerja, Produktivitas PT.PN IV Unit Pabatu.

\begin{abstract}
This study was conducted to determine the effect of work discipline on employee productivity at PT. Perkebunan Nusantara IV (Persero) Pabatu Business Unit. The population in this study were all employees of the department, engineering / processing, and general at PT. Perkebunan Nusantara IV (Persero) Unit Business Unit is 1031 people. the number of respondents used in this study were 104 people. The research was obtained from the results of the t test on the variables obeying all company regulations, namely 2.652 $>$ T table $=1.980$ stating that complying with all company regulations had a positive and significant effect on employee work productivity. Effective use of time is 3,069 < Ttable =1,980 stating that effective use of time has a positive and significant effect on employee work productivity variables. Responsibility for work and assignments is 5,467> T table $=1.980$ states that work responsibilities and tasks have positive and significant to employee work productivity. The absentee level of 1,200 <Ttable = 1,980 has a positive and insignificant effect on employee work productivity.. And the $R$ value obtained is 0.884 . This figure shows that $88.4 \%$ of work productivity is explained by the variable workdiscipline.
\end{abstract}

Keywords: Work Discipline, Productivity PT.PN IV Unit Pabatu.

How to Cite: Andini, Y. Lubis, Y., \& Siregar, R.S. 2019. Pengaruh Disiplin Kerja Terhadap Produktivitas Kerja Karyawan Pt Perkebunan Nusantara IV (Persero) Unit Usaha Pabatu. Jurnal Agriuma. 1(2): 68 -77. 


\section{PENDAHULUAN}

Karyawan menjadi salah satu faktor penting yang dapat menentukan keberhasilan tujuan perusahaan. Hal ini terjadi karena karyawan adalah penggerak utama roda kegiatan sebuah perusahaan. Dalam melakukan kegiatan,karyawan memerlukan petunjuk kerja atau pemberitahuan bagaimana melaksanakan sebuah pekerjaan dari perusahaan agar pelaksanaan pekerja tersebut sesuai dengan perencanaan yang telah dibuat perusahaan.

Disiplin kerja adalah suatu sikap, perilaku yang dilakukan secara sukarela dan penuh kesadaran serta keadaan untuk mengikuti peraturan yang telah ditetapkan perusahaan baik tertulis maupun tidak tertulis (Nitisemito, 2002:199). Kedisiplinan merupakan salah satu fungsi operatif dari manajer karena semakin disiplin karyawan, semakin tinggi prestasi kerja yang dapat dicapainya dan akan menciptakan karyawan yangberkualitas.

Produktivitas tidak hanya ditujukan untuk mendapatkan hasil kerja yang sebanyakbanyaknya, melainkan kualitas kerja karyawan yang perlu diperhatikan. Hal ini juga berlaku bagi karyawan PT. Perkebunan Nusantara IV dalam melaksanakan pekerjaannya dengan kualitas kerja yang baik sehingga dapat mencapai produktivitas kerja yang tinggi.

Salah satu perusahaan yang bergerak dibidang pertanian yaitu PT. Perkebunan Nusantara IV (persero) yang memiliki Grup Unit Usaha yang dibangun oleh perusahaan perkebunan dengan kelengkapan fasilitas pengolahan yang dimiliki oleh perusahaan perkebunan tersebut. Kebun unit Usaha Pabatu memiliki komuditi yaitu kelapa sawit,dengan jumlah karyawan pada tahun 2016 sebanyak 1065 orang. Perkembanngan jumlah dan komposisi karyawan pada PT.Perkebunan Nusantara IV Unit Usaha Pabatu dari tahun 2013 sampai 2017 dapat dilihat secara lengkap pada tabel 1.

Tabel 1.Luas Lahan/Ha, Produksi Kelapa Sawit/Ton Tahun Dan Jumlah Karyawan Tahun 2013-2016

\begin{tabular}{cccc}
\hline Tahun & $\begin{array}{c}\text { Luas } \\
\text { Lahan/ha }\end{array}$ & $\begin{array}{c}\text { Produksi } \\
\text { Kelapa Sawit/Ton }\end{array}$ & $\begin{array}{c}\text { Jumlah } \\
\text { Karyawan }\end{array}$ \\
\hline 2013 & 4562 & $95.592,070$ & 1063 \\
2014 & 4398 & $93.371,340$ & 1085 \\
2015 & 4230 & $84.030,050$ & 1018 \\
2016 & 3768 & $69.180,100$ & 1065 \\
2017 (RKAP) & 2983 & 71.100 & 1031 \\
\hline
\end{tabular}

Sumber: Profil Unit Usaha Pabatu Desember 2016

Berdasarkan tabel 1 jumlah karyawan kebun unit Pabatu terjadi kenaikan dan penurunan hampir disetiap tahun mulai dari tahun 2013 sampai dengan 2017. Kenaikan 
dan penurunan ini tidak sejalan dengan penurunan luas lahan yang terjadi pada kebun unitPabatu.

PT.Perkebunan Nusantara IV Unit Usaha Pabatu memiliki struktur organisasi dengan bagian afdeling,teknik/pengolahan dan umum dengan jumlah karyawan yang berbedabeda. Maka secara lengkap jumlah karyawan berdasarkan bagian ini dapat dilihat Pada tabel 2 .

Tabel 2. Jumlah karyawan kebun unit pabatu berdasarkan bagian-bagian

\section{Tahun Afdeling/bahagian Teknik/ Umum Total}

\begin{tabular}{cccccc} 
Karyawan & $\begin{array}{c}\text { Karyawan } \\
\text { tetap }\end{array}$ & Pengolahan & & \\
\cline { 2 - 6 } & 316 & 314 & 318 & 115 & 1063 \\
2013 & 327 & 326 & 322 & 110 & 1085 \\
2014 & 298 & 297 & 320 & 103 & 1018 \\
2016 & 318 & 317 & 317 & 113 & 1065 \\
2017 & 318 & 301 & 305 & 107 & 1031 \\
\hline
\end{tabular}

Sumber : Profil Unit Usaha Pabatu Tahun 2016.

Pada tabel 2 menjelaskan terjadi penurunan mampu kenaikan pada jumlah karyawan, dimana pada bagian afdeling terjadi kenaikan namun pada bagian teknik/pengolahan dan umum terjadi penurunan. Diketahui bahwa dari keseluruhan karyawan tersebut setiap tahunnya masih dijumpai penurunan,hal ini diduga menandakan masih kurangnya disiplin kerja karyawan dibagian keseluruhan afdeling (karyawan tetap dan tidak tetap) teknik/pengolahan,umum dan total pada PT.Perkebunan Nusantara IV Unit UsahaPabatu.

Berdasarkan hasil prasurvey yang dilakukan pada bulan mei 2017 pada bagian SDM PT.Perkebunan Nusantara IV Unit Usaha Pabatu menyatakan dalam hal upaya menciptakan disiplin kerja karyawan PT.Perkebunan Nusantara IV Unit Usaha Pabatu masih terdapat banyak kendala yang dihadapi seperti tingkat absensi karyawan dan peraturan kerja yang masih belum sepenuhnya diterapkan terhadap pelanggaran disiplin kerja sehingga sulit untuk mencapai kemaksimalan produktivitasperusahaan.

Berdasarkan uraian latar belakang, makapeneliti ingin mengetahui bagaimana pengaruh disiplin kerja terhadap produktivitas kerja karyawan pada PT.Perkebunan Nusantara IV (Persero) Unit Usaha Pabatu. 


\section{METODE PENELITIAN}

Penentuan lokasi ini dilakukan secara purposive (sengaja). Hal ini bardasarkan data PT. Perkebunan Nusantara IV Unit Usaha Pabatu dimana desa Pabatu kecamatan Dolok Merawan Tebing Tinggi merupakan salah satu pusat perkebunan kelapa sawit di Sumatera Utara. Adapun penelitian ini dilaksanakan pada bulan Agustus 2017 sampai dengan September 2017 .

Populasi dalam penelitian ini adalah semua karyawan yang ada di PT.Perkebunan Nusantara IV Unit Pabatu berjumlah 1031 orang, yang terdiri dari afdeling/bagian berjumlah 619 orang,teknik/pengolahan berjumlah 305 orang ,umum berjumlah 107 orang. Metodepengambilan sampel yang digunakan adalah stratifaied random sampling. Data yang dikumpulkan dalam penelitian ini terdiri dari data primer dan data sekunder.

Hipotesis yang diajukan dalam penelitian ini diuji dengan menggunakan analisis regresi linier berganda. Produktivitas kerja sebagai variabel terikat, sedangkan disiplin kerja sebagai variabel bebas, terdiri dari mematuhi semua peraturan perusahaan, penggunaan waktu secara efektif, tanggungjawab dalam pekerjaan dan tugas, tingkat absensi. Model regresi yang digunakan adalah:

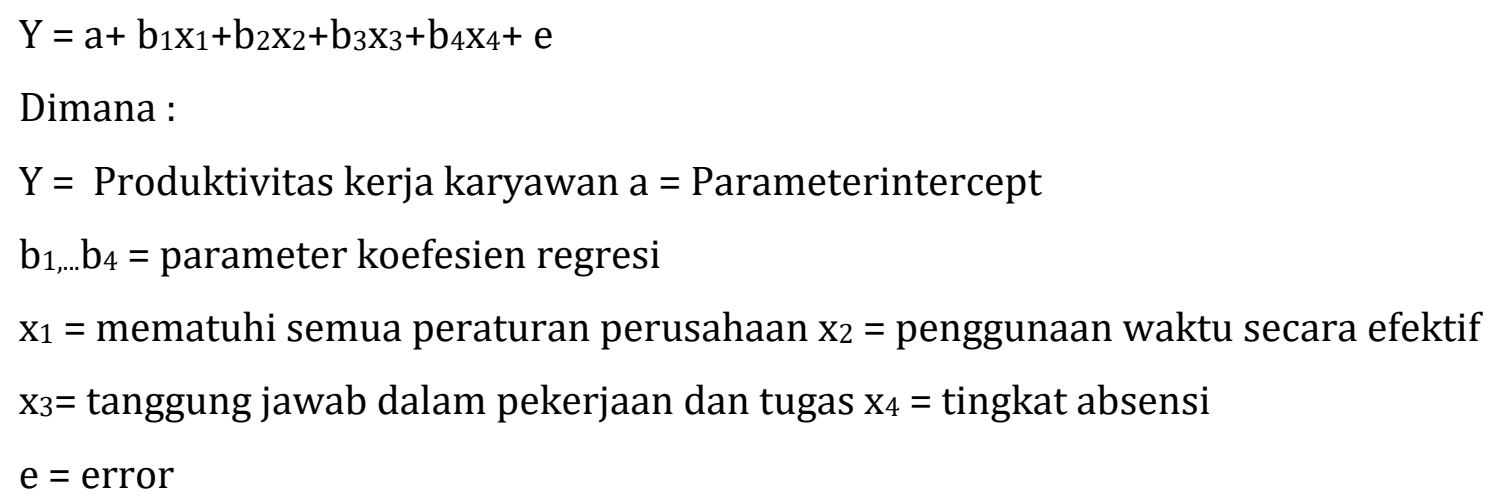

\section{HASIL DAN PEMBAHASAN}

\section{Regresi}

Untuk pengujian hipotesis yang diajukan diterima atau ditolak, digunakan uji F dengan ketentuan jika $F_{\text {hitung }} \geq \mathrm{F}_{\text {tabel }}$ maka $\mathrm{H}_{0}$ ditolak dan $\mathrm{H}_{1}$ diterima, sebaliknya apabila $\mathrm{F}_{\text {hitung }} \leq$ $\mathrm{F}_{\text {tabel }}$ maka $\mathrm{H}_{0}$ diterima $\mathrm{H}_{1}$ ditolak. Sedangkan pengujian secara persial masing-masing variabel indenpenden dimaksudkan untuk mengetahui apakah secara individual variabel Disiplin kerja ( mematuhi semua peraturan perusahaan, penggunaan waktu secara efektif, tanggung jawab dalam pekerjaan dan tugas, tingkat absensi) mempunyai pengaruh yang 
nyata atau tidak terhadap variabel produktivitas kerja karyawan. Untuk pengujian secara persial digunakan uji t dengan ketentuan jika thitung $\geq$ tabel maka $\mathrm{H}_{0}$ ditolak dan $\mathrm{H}_{1}$ diterima, sebaliknya apabila $t_{\text {hitung }} \leq t_{\text {tabel }}$ maka $\mathrm{H}_{0}$ diterima dan $\mathrm{H}_{1}$ ditolak.

Selanjutnya berdasarkan nilai koefesien determinasi $\left(\mathrm{R}^{2}\right)$ diketahui besarnya pengaruh perubahan disiplin kerja (mematuhi semua peraturan perusahaan, penggunaan waktu secara efektif, tanggung jawab dalam pekerjaan dan tugas, tingkat absensi) terhadap produktivitas kerja karyawan pada PT.Perkebunan Nusantara IV Unit Usaha Pabatu.

Table 3. Koefesien Determinasi

\begin{tabular}{ccccc}
\hline Model & $\mathrm{R}$ & RSquare & AdjustedRSquare & Std. Error of theEstimate \\
\hline 1 & $.940^{\mathrm{a}}$ & .884 & .879 & 3.13095
\end{tabular}

a. Predictors: (Constant), absensi, tanggungjawab, waktu,peraturan

b. Dependent Variable:Y

Nilai koefesien determinasi sebesar 0,884 berarti bahwa perubahan produktivitas kerja karyawan pada PT.Perkebunan Nusantara IV Unit Usaha Pabatu dapat dijelaskan oleh perubahan disiplin kerja (mematuhi semua peraturan perusahaan, penggunaan waktu secara efektif, tanggung jawab dalam pekerjaan dan tugas, tingkat absensi) sebesar $88,4 \%$. Sedangkan sisanya sebesar $1,6 \%$ dipengaruhi oleh variabel lain yang tidak dianalisis dalam penelitia ini.

\section{Uji Serempak (Uji F)}

Pengaruh variabel disiplin kerja ( mematuhi semua peraturan perusahaan, penggunaan waktu secara efektif, tanggung jawab dalam pekerjaan dan tugas, tingkat absensi ) terhadap variabel produktivitas kerja karyawan dapat dilihat pada tabel berikut.

Tabel 4.Hasil Uji Serempak

\begin{tabular}{llrrrrr}
\hline Model & & Sum of Squares & df & MeanSquare & \multicolumn{1}{c}{ F } & \multicolumn{1}{c}{ Sig. } \\
\hline 1 & Regression & 7362.900 & 4 & 1840.725 & 187.774 & $.000^{\mathrm{b}}$ \\
& Residual & 970.484 & 99 & 9.803 & & \\
& Total & 8333.385 & 103 & & & \\
\end{tabular}

a. Predictors: (Constant), absensi, tanggungjawab, waktu,peraturan

b. Dependent Variable:Y

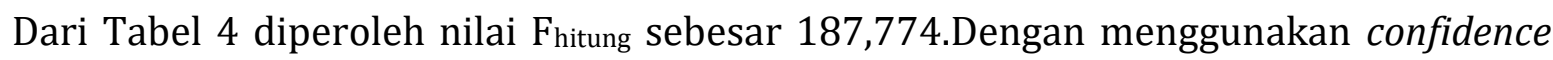
interval (CI) $95 \%$ df 5:99 ( $\alpha=0,05)$ maka dari tabel distribusi $\mathrm{F}$ diperoleh nilai 2,31. 


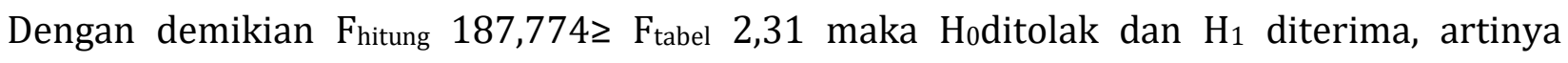
variabel disiplin kerja (mematuhi semua peraturan perusahaan, penggunaan waktu secara efektif, tanggung jawab dalam pekerjaan dan tugas, tingkat absensi) berpengaruh signifikan terhadap produktivitas kerja karyawan pada PT.Perkebunan Nusantara IV Unit UsahaPabatu.

Pada Tabel 4 dilihat nilai signifikan sebesar 0,000 lebih kecil dari $\alpha=0,05$, hal ini berarti bahwa variabel disiplin kerja (mematuhi semua peraturan perusahaan, penggunaan waktu secara efektif, tanggung jawab dalam pekerjaan dan tugas, tingkat absensi) memiliki berpengaruh yang signifikan. Hal ini berarti bahwa secara serempak variabel disiplin kerja (mematuhi semua peraturan perusahaan, penggunaan waktu secara efektif, tanggung jawab dalam pekerjaandan tugas, tingkat absensi) menunjukkan pengaruh sangat nyata terhadap produktivitas kerja karyawan pada PT.Perkebunan Nusantara IV Unit Usaha Pabatu.

\section{Uji Persial (Uji t)}

Uji pengaruh variabel disiplin kerja (mematuhi semua peraturan perusahaan, penggunaan waktu secara efektif, tanggung jawab dalam pekerjaan dan tugas, tingkat absensi) secara persial dapat dilihat pada tabel 5.

Tabel 5. Hasil Uji Persial

\begin{tabular}{lcclrr} 
& \multicolumn{2}{c}{ Unstandardized } & \multicolumn{2}{l}{ Standardized } \\
Coefficients & \multicolumn{2}{c}{ Coefficients } & \\
Model & $\mathrm{B}$ & Std.Error & Beta & $\mathrm{t}$ & Sig. \\
\hline (Constant) & .785 & 1.232 & & .637 & .525 \\
\hline Peraturan & .470 & .177 & .277 & 2.652 & .009 \\
\hline Waktu & .524 & .171 & .262 & 3.069 & .003 \\
\hline Tanggungjawab & .722 & .132 & .369 & 5.467 & .000 \\
\hline Absensi & .176 & .147 & .088 & 1.200 & .233 \\
\hline
\end{tabular}

a. Predictors: (Constant), absensi, tanggungjawab, waktu,peraturan

b. Dependent Variable: $Y$

Sumber: Hasil Penelitian 2018 (Data Diolah)

Berdasarkan nilai koefesien regresi (B) hasil analisis, maka diperoleh persamaan regresi sebagai berikut:

$$
Y=0,785+0,470 X_{1}+0,524 X_{2}+0,72 X_{3}+0,176 X_{4}
$$


Dari hasil pengolahan data menggunakan software SPSS didapat nilai t pada Tabel 5.Uji t menunjukkan seberapa besar pengaruh variabel bebas secara individual terhadap variabel terikat. Uji t dilakukan dengan cara membandingkan perbedaan antara nilai dua nilai rata-rata dengan standard error dari perbedaan rata-rata dua sampel. Hipotesis dalam Uji t adalah:

$\mathrm{H}_{0}$ : Disiplin Kerja (X) tidak berpengaruh signifikan terhadap Produktivitas Kerja (Y). $\mathrm{H}_{1}$ : Displin Kerja (X) berpengaruh signifikan terhadap ProduktivitasKerja(Y).

Tingkat kepercayaan yang digunakan adalah 95\%, maka $\alpha=0,05$. Kriteria pengambilan keputusan adalah :

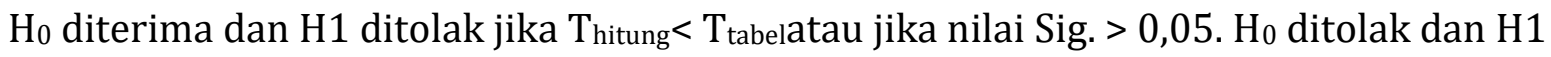

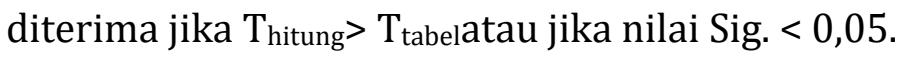

Melalui Tabel 5 hasil uji signifikan secara pasial dapat diambil kesimpulan yaitu variabel Peraturan $\left(X_{1}\right)$ mempunyai nilai sebesar 0,009 dan lebih kecil dari $\alpha=0,05$ dan $\mathrm{T}_{\text {hitung }}=2,652>\mathrm{T}_{\text {tabel }}=1,980$ maka $\mathrm{H}_{0}$ ditolak dan $\mathrm{H}_{1}$ diterima, yang berarti bahwa variabel mematuhi semua peraturan perusahaan $\left(\mathrm{X}_{1}\right)$ secara parsial berpengaruh positif dan signifikan terhadap variabel Produktivitas Kerja (Y) pada PT. Perkebunan Nusantara IV Unit Usaha Pabatu. Artinya jika mematuhi semua peraturan perusahaan ditingkatkan, maka produktivitas kerja karyawan pada PT. Perkebunan Nusantara IV Unit Usaha Pabatu pun meningkat.

Hasil uji signifikan secara parsial dapat diambil kesimpulan yaitu variabel Penggunaan waktu secara efektif $\left(\mathrm{X}_{2}\right)$ mempunyai nilai sebesar 0,003 dan lebih kecil dari $\alpha=0,05$ dan $\mathrm{T}_{\text {hitung }}=3,069<\mathrm{T}_{\text {tabel }}=1,980$ maka $\mathrm{H} 0$ ditolak dan $\mathrm{H} 1$ diterima, yang berarti bahwa variable Penggunaan Waktu Secara Efektif $\left(\mathrm{X}_{2}\right)$ secara parsial berpengaruh positif dan signifikan terhadap variabel Produktivitas Kerja (Y) pada PT. Perkebunan Nusantara IV Unit Usaha Pabatu. karena $\mathrm{T}_{\text {hitung }}$ lebih kecil dari $\mathrm{T}_{\text {tabel }}$ maka variabel disiplin kerja dikatakan signifikan dalam penelitian ini Artinya jika penggunaan waktu secara efektifditingkatkan, maka produktivitas kerja karyawan pada PT. Perkebunan Nusantara IV Unit Usaha Pabatu akan meningkat.

Hasil uji signifikan secara pasial dapat diambil kesimpulan yaitu variabel Tanggung jawab $\left(\mathrm{X}_{3}\right)$ mempunyai nilai sebesar 0,000 dan lebih kecil dari $\alpha=0,05$ dan $\mathrm{T}_{\text {hitung }}=5,467>$ $\mathrm{T}_{\text {tabel }}=1,980$ maka variabel tanggung jawab dalam pekerjaan dan tugas $\left(\mathrm{X}_{3}\right)$ secara parsial berpengaruh positif dan signifikan terhadap variabel Produktivitas Kerja (Y) pada PT. 
Perkebunan Nusantara IV Unit Usaha Pabatu. Artinya jika Tanggung jawab dalam pekerjaan dan tugas ditingkatkan, maka produktivitas kerja karyawan pada PT. Perkebunan Nusantara IV Unit Usaha Pabatu punmeningkat.

Hasil uji signifikan secara pasial dapat diambil kesimpulan yaitu variabel TingkatAbsensi $\left(\mathrm{X}_{4}\right)$ mempunyai nilai sebesar $\mathrm{T}_{\text {hitung }}=1,200<\mathrm{T}_{\text {tabel }}=1,980$ maka variabel Tingkat Absensi $\left(\mathrm{X}_{4}\right)$ secara parsial berpengaruh positif dan tidak signifikan terhadap variabel Produktivitas Kerja (Y) pada PT. Perkebunan Nusantara IV Unit Usaha Pabatu. Artinya jika Absensi ditingkatkan, maka produktivitas kerja karyawan pada PT. Perkebunan Nusantara IV Unit Usaha Pabatu menurun. Berdasarkan hasil analisis diketahui bahwa nilai koefesien regresi yang paling tinggi adalah variabel $\left(\mathrm{X}_{3}\right)$. Hal ini berarti bahwa tanggung jawab dalam pekerjaan dan tugas berpengaruh lebih dominan terhadap produktivitas kerja karyawan pada PT.Perkebunan Nusantara IV Unit Usaha Pabatu.

Hasil analisis menunjukkan bahwa secara simultan, variabel disiplin kerja berpengaruh signifikan terhadap produktivitas kerja karyawan pada PT.Perkebunan Nusantara IV Unit Usaha Pabatu.Pemberian disiplin kerja merupakan salah satu bentuk motivasi yang dilakukan perusahaan dengan tujuan agar produktivitas kerja karyawan meningkat. Pemberian disiplin kerja tidak secara langsung meningkat produktivitas, tetapi terlebih dahulu akan mendorong atau meningkatkan semangat kerja karyawan, sehingga dengan semangat kerja yang semakin meningkat maka produktivitas kerja akan meningkat. Hasil penelitian Hasibuan (2009) dapat menjadi acuan terhadap hal tersebut, dimana variabel disiplin kerja yang bersifat ekonomis mempunyai pengaruh signifikan dan pengaruh positif terhadap variabel produktivitas kerjakaryawan.

Hasil penelitian menunjukkan bahwa koefesien determinasi disiplin kerja berpengaruh positif dan signifikan terhadap produktivitas kerja karyawan pada PT. Perkebunan Nusantara IV Unit Usaha Pabatu, dibuktikan dengan koefisien sebesar 88,4\% sedangkan sisanya 11,6\%. Maka dapat disimpulkan bahwa hipotesis kedua diterima. Perlu dijelaskan bahwa dari analisis deskriptif semua variabel kerja baik dari variabel mematuhi semua peraturan perusahaan $\left(\mathrm{X}_{1}\right)$,penggunaan waktu secara efektif $\left(\mathrm{X}_{2}\right)$, tanggung jawab dalam pekerjaan dan tugas $\left(\mathrm{X}_{3}\right)$, tingkat absensi $\left(\mathrm{X}_{4}\right)$ dan produktivitas kerja menunjukkan baik dari semua variabel. 
Kedisiplinan suatu perusahaan dikatakan baik, jika sebagian besar karyawan menaati peraturan-peraturan yang ada,penggunaan waktu secara efektif,tanggung jawab dalam pekerjaan dan tugas,tingkat absensi dilakukan makadalam meningkatkan kedisiplinan dan mendidik karyawan supaya menaati semua peraturan perusahaan. Pemberian hukuman harus adil dan tegas terhadap semua karyawan.Dengan keadilan dan ketegasan, sasaran pemberian hukuman tercapai.Peraturan tanpa diimbangi dengan pemberian hukuman yang tegas bagi pelanggarannya bukan menjadi alat pendidik bagi karyawan.Tanpa dukungan disiplin karyawan yang baik, sulit bagi perusahaan untuk mewujudkan tujuannya. Dalam usaha meningkatkan produktivitas kerja karyawan salah satu cara yang dapat dilakukan yaitu dengan memperhatikan disiplin kerja karyawan. Seseorang akan melaksanakan tugasnya dengan baik dan penuh rasa tanggung jawab bila karyawan tersebut memiliki disiplin kerja yang tinggi. Untuk mengusahakan selalu terbinanya sikap disiplin kerja yang tinggi, maka diperlukan peraturan dan hukuman dalam perusahaan tersebut.

\section{SIMPULAN}

Berdasarkan hasil penelitian dan pembahasan dapat ditarik kesimpulan bahwa disiplin kerja yang terdiri dari : Mematuhi semua peraturan perusahaan, penggunaan waktu secara efektif, tanggung jawab dalam bekerja, dan tingkat absensi maka disiplin kerja karyawan pada PT. Perkebunan Nusantara IV Unit Usaha Pabatu dengan kategori baik. Secara serempak, variabel disiplin kerja berpengaruh terhadap produktivitas kerja karyawan pada PT.Perkebunan Nusantara IV Unit Usaha Pabatu. Dengan nilai Fhitungsebesar 262,880 $\geq \mathrm{F}_{\text {tabel }}$ 2,31maka $\mathrm{H}_{0}$ ditolak dan $\mathrm{H}_{1}$ diterima artinya variabel disiplin kerja berpengaruh signifikan terhadap produktivitas kerja karyawan pada PT.Perkebunan Nusantara IV Unit Usaha Pabatu. Secara parsial, variabel mematuhi semua peraturan perusahaan berpengaruh signifikan terhadap produktivitas kerja karyawan di PTPN IV Unit Usaha Pabatu dengan nilai $\mathrm{T}_{\text {hitung }}=4,423>\mathrm{T}_{\text {tabel }}=1,980$, penggunaan waktu secara efektif berpengaruh signifikan terhadap produktivitas kerja karyawan pada PTPN IV Unit Usaha Pabatu dengan nilai $\mathrm{T}_{\text {hitung }}=3,069<\mathrm{T}_{\text {tabel }}=1,980$, tanggung jawab dalam pekerjaan dan tugas berpengaruh signifikan terhadap produktivitas kerja karyawan PTPN IV Unit Usaha Pabatu dengan nilai $\mathrm{T}_{\text {hitung }}=5,467>\mathrm{T}_{\text {tabel }}=1,980$,dan variabel tingkat absensi berpengaruh tidak signifikan terhadap produktivitas kerja karyawan pada PTPN IV Unit Pabatu dengan nilai $\mathrm{T}_{\text {hitung }}=1,200<\mathrm{T}_{\text {tabel }}=1,980$ 


\section{DAFTAR PUSTAKA}

Bagus, Denny. 2009. Disiplin Kerja Karyawan-Jurnal Manajemen, Bahan Kuliah (http://jurnalsdm.blogspot.com) dikutip pada tanggal 13 September 2015 Jam 00:54 WIB

Delli Mustopa. 2014. "Analisis Pengaruh Motivasi, Kompensasi, Dan Komitmen Karyawan Terhadap Disiplin Kerja Karyawan Rumah Sakit Daerah Banyuasin”. Tidak Dipublikasikan. Skripsi. Palembang: Universitas Bina Darma.

Ghozali, Imam. 2005. Aplikasi Analisis Multivariate dengan Program SPSS,Edisi Kedua.

Badan Penerbit Universitas Diponegoro. Semarang.

Hasibuan, Melayu S.P (2010). Manajemen Sumber Daya Manusia, PT BumiAksara. Jakarta Herbyantoro Adiwijaya. 2011. "Pengaruh Komitmen Karyawan, Kepuasan

Kerja, Kepemimpinan Transaksional Terhadap Kinerja Karyawan Pada Lembaga Pendidikan STIE YKP Yogyakarta". Tidak Dipublikasikan. Tesis. Yogyakarta: MM UPN Veteran.

Marhaendra Kusuma. 2012. Pengaruh gaya kepemimpinan partisipatif, Kompensasi, dan motivasi terhadap kinerja Karyawan di Sekolah Tinggi dan Politeknik Cahaya Surya Kediri. Jurnal Ilmu Manajemen, REVITALISASI, Vol. 1, Nomor 3, Desember 2012 Mangkunegara, AA. Anwar Prabu. 2011. Manajemen Sumber Daya ManusiaPerusahaan, PT Remaja Rosdakarya.

Marpaung, Rio. 2013. Pengaruh Faktor Disiplin Kerja dan pengawasan Kerja Terhadap Produktivitas Kerja Karyawan Pada PT.Perkebunan XYZ Pabrik Kelapa Sawit ABC Desa Balai Jaya Sinembah Rokan HilirRiau. Skripsi. Universitas Riau, Pekanbaru

Novani Cipta Dewi dan Edy Mulyantomo. (Tanpa Tahun). "Pengaruh Kepemimpinan, Kepuasan Kerja Dan Disiplin Kerja Terhadap Kinerja Karyawan (Studi empiris pada karyawan di PT. Mataram Cakrawala Televisi Indonesia-Semarang)". Tidak Dipublikasikan.Skripsi. Semarang: Fakultas Ekonomi Universitas Semarang.

Rivai Veithzal, 2011, Manajemen Sumber Daya Manusia Untuk Perusahaan,Cetakan keempat, PT. Raja Grafindo Persada,Jakarta.

Roza, Rokky. 2012. Pengaruh Disiplin Kerja Terhadap Produktivitas Kerja Karyawan Pada PT. Multi Palma Sejahtera Bandar Sei. Kijang Kabupaten Pelalawan. Skripsi.

Universitas Islam Riau, Pekanbaru

Syarifuddin. 2012. "Pengaruh Motivasi dan Kepuasan Kerja Terhadap Disiplin Kerja Pegawai UPTD Pendidikan Kecamatan Sepenggal Kabupaten Bungo. Tidak Dipublikasikan”. Skripsi.Jambi: Manajemen Program Pascasarjana Universitas Pascasarjana Jambi.

Suratiyah, 2008. Pengaruh Motivasi Kerja dan Kemampuan Kerja Karyawan Terhadap Produktivitas Kerja Karyawan pada PT.Safilindo Permata.Jurnal Strategic,Volume 7,Nomor 14 september

Sinurat, novriadi.2012. Pengaruh Pengawasan Mandor Terhadap Produktivitas Karyawan Pada PT. Perkebunan Nusantara V Sei Galuh.Skripsi. UniversitasRiau,

Sondang P. Siagian. 2008. Manajemen Sumber Daya Manusia, Edisi Revisi,Penerbit Gunung Agung, Jakarta.

Widia Agustina dan Lila Bismala. 2014. Dampak Pengawasan Dan Kepuasan Kerja Dalam Mempengaruhi Disiplin Kerja Karyawan PT. Perkebunan Nusantara IV (Persero) Medan. Jurnal RisetAkuntansi Dan Bisnis Fakultas Ekonomi UniversitasMuhammadiyah Sumatera Utara, Vol 14 (1): 125-136. 